\title{
Growing up and moving on. A multicentre UK audit of the transfer of adolescents with juvenile idiopathic arthritis from paediatric to adult centred care
}

\author{
L P Robertson, J E McDonagh, T R Southwood, K L Shaw, on behalf of the British \\ Society of Paediatric and Adolescent Rheumatology
}

See end of article for authors' affiliations

\section{Correspondence to:} Dr Janet E McDonagh, Institute of Child Health Diana, Princess of Wales Children's Hospital, Steelhouse Lane, Birmingham B4 $6 \mathrm{NH}$, UK; j.e.mcdonagh@bham.ac. uk

Accepted 14 June 2005 Published Online First 30 June 2005

\begin{abstract}
Objective: To assess the provisions made for the transfer of adolescents with juvenile idiopathic arthritis to adult rheumatology clinics in the UK and the impact of a transitional care programme.

Methods: An audit of the documentation of the provisions made for transfer in 10 centres participating in a controlled trial of transitional care. Each centre conducted a retrospective case note audit of the recent patients transferred to adult care before and 12-24 months after the start of the trial. Demographic details, age when transition was first discussed, age at transfer, transitional issues, multidisciplinary team involvement, adolescent self advocacy, and readiness were documented.

Results: There were improvements at follow up in documentation of transitional issues, disease specific educational needs, adolescent readiness, and parental needs with the exception of dental care, dietary calcium, and home exercise programmes. The age at which the concept of an independent clinic visit was introduced was lower (mean (SD): 16.8 (1.06) v 15.8 (1.46) years, $p=0.01$ ) but there were no other changes in age related transitional milestones. Significantly more participants had preparatory visits to the adult clinic, had a transition plan, and had joint injections while awake at follow up.

Conclusions: The improvement in documentation suggests that involvement in the research project increased awareness of transitional issues. The difficulty of changing policy into practice was highlighted, with room for improvement, particularly at the paediatric/adult interface. The reasons for this are likely to be multiple, including resources and lack of specific training.
\end{abstract}

A dolescents with juvenile idiopathic arthritis (JIA) and their parents have reported that transfer from paediatric to adult services in the United Kingdom is associated with many difficulties. Along with families of children who have other chronic illnesses, they have called for greater preparation and increased professional liaison during this time. ${ }^{12}$ Transition is defined as a multifaceted active process that attends to the medical, psychosocial, educational, and vocational needs of adolescents as they move from child to adult centred care. This is in contrast to transfer, which is an event rather than a process. Transition programmes for adolescents with chronic diseases aim to provide coordinated, uninterrupted health care that is age and developmentally appropriate and comprehensive. They promote skills in communication, decision making, and self care and therefore enhance a young person's control and independence.

There are many differences between adult and paediatric care. ${ }^{3}{ }^{4}$ Young people need to be aware of these differences and to be equipped with knowledge and skills to allow them to interact effectively with their new adult health care providers. Conversely, adult providers need to be aware of the dramatic change that these young people experience at this time. The need for this aspect of care provision has been highlighted by several professional bodies ${ }^{5-8}$ and recently has been recognised as a core standard of care for children with lifelong chronic illness in the UK's National Service Framework of Children, Young People and Maternity Services (NSF). ${ }^{9}$ Preliminary data from the first controlled trial of transitional care in any chronic illness showed significant improvement in health related quality of life, disease related knowledge, satisfaction in health care, and vocational readiness markers ${ }^{10-13}$ Our aims in the present study were to audit the documentation of the provisions made for the transfer of young people with JIA from the trial centres to adult health services and to assess indirectly the impact of the coordinated transitional care programme ${ }^{11}$ developed in response to a prior needs assessment $^{2}{ }^{14-17}$ on transfer.

\section{METHODS}

A retrospective case note audit of recent patients with JIA transferred to adult centred rheumatology care was conducted in 10 participating UK paediatric rheumatology centres before and 12 to 24 months after the implementation of a structured coordinated programme of transitional care. ${ }^{11}$ All but one of the centres had been identified previously in an audit of adolescent rheumatology care. ${ }^{18}$ The controlled trial of the implementation of the transitional care programme enrolled participants at ages 11,14 , and 17 years and therefore represented a minority of the patients audited. Full details of the trial cohort have been described elsewhere. ${ }^{10}$ Data collected included demographic details, age when transition was first discussed, when transfer occurred, transitional care components, documentation of transitional issues and needs, multidisciplinary team (MDT) involvement, and details about the adult rheumatology service involved. Comparisons were made between the baseline and follow up data for actual data values where applicable and the documentation of information in the medical notes.

Abbreviations: AHP, allied health professionals; $C H A Q$, Childhood Health Assessment Questionnaire; CNS, clinical nurse specialists; JIA, juvenile idiopathic arthritis; MDT, multidisciplinary team; NSF, National Service Framework 
Table 1 Baseline and follow up participants by centre and project involvement

\begin{tabular}{llll}
\hline Centre & $\begin{array}{l}\text { Baseline, } \\
\mathbf{n = 1 2 8}(\%)\end{array}$ & $\begin{array}{l}\text { Follow up, } \\
\mathbf{n = 9 3}(\%)\end{array}$ & $\begin{array}{l}\text { Number of participants } \\
\text { enrolled into transition } \\
\text { project" }\end{array}$ \\
\hline 1 & $20(15.6)$ & $39(42)$ & 18 \\
2 & $20(15.6)$ & $4(4.3)$ & 2 \\
3 & $18(14.1)$ & $12(12.9)$ & 7 \\
4 & $10(7.8)$ & $10(10.8)$ & 2 \\
5 & $21(16.4)$ & $15(16.1)$ & 0 \\
6 & $20(15.6)$ & $8(8.6)$ & 3 \\
7 & $17(13.3)$ & $5(5.4)$ & 3 \\
8 & $2(1.6)$ & 0 & 0 \\
\hline \multirow{4}{*}{ *Missing data for eight patients. } \\
\hline
\end{tabular}

All participants gave written informed assent/consent before assessment, and the project had multicentre (West Midlands) and local research ethics committee approval in each of the participating centres.

\section{Statistical analyses}

Non-parametric data was analysed using the Mann-Whitney $\mathrm{U}$ test, and nominal data using the Pearson $\chi^{2}$ test. Patients less than 21 years were compared with those 21 years or older at time of transfer to assess if these older patients were affecting the overall results. Data was also analysed with respect to participation in the transitional care project at follow up. Probability (p) values of 0.05 or less were considered significant. Data was analysed using SPSS software version X (SPSS Ltd, Woking, UK).

\section{RESULTS}

Data from the initial audit with the first 110 patients have been published elsewhere. ${ }^{18}$ Data from the second round were available for 93 patients. These were compared with the data from the initial audit, which recruited 128 patients. There were proportionally more male subjects in the follow up audit than in the first audit $(30 \% v 43 \% ; \mathrm{p}=0.05)$ and less co-morbidity ( $39 \%$ v 20\%; $\mathrm{p}=0.007)$. Median age at transfer was the same in both groups ( 18 years (range 12 to 49) $v 18$ years (range 15 to 40 ); $p=0.26$ ). If the over $21 \mathrm{~s}$ were excluded from analyses, median ages at transfer were 17 ( 12 to 20) years and 18 ( 15 to 20) years at baseline and follow up, respectively, and not significantly different $(p=0.09)$. There were no differences in the age at onset of JIA or in the proportions of JIA subtypes. The patient numbers per centre are shown in table 1. Forty one per cent of the follow up group were recruited to the transitional care project (table 1).

\section{Self advocacy skills}

There were significant improvements in the documentation of self advocacy skills (table 2).

Comparing the actual age related data between the two groups the only difference was in the age at which the concept of independent clinic visits was introduced. This was lower at follow up (table 3) and this difference was maintained when patients $\geqslant 21$ years were excluded from the analysis (mean (SD): 16.8 (1.1) v 15.7 (1.39) years, $\mathrm{p}=0.006)$.

\section{Parents}

There was improved documentation of the transitional needs of parents at follow up $(1.7 \% \vee 26.7 \%, \mathrm{p}<0.001)$ and also whether concurrent visits for parents were documented when the young person was seen independently $(39.7 \% \vee 60 \%$, $\mathrm{p}=0.003)$, but there was no difference in the actual proportions of parents seen separately between the baseline and follow up groups $(31.3 \%$ v 37.0\%, $\mathrm{p}=0.54)$.

\section{Involvement of the multidisciplinary team}

The majority of discussions about transition occurred as an outpatient $(92.2 \%$ and $96.8 \%$ in baseline and follow up groups, respectively). There were no differences in the proportion of "transition discussions" involving different health care professionals (consultant, specialist registrars, clinical nurse specialist, physiotherapist, occupational therapist, social worker). However, there was significant improvement in the continuity of senior medical staff during the transition process $(58.4 \% \vee 87.1 \%, \mathrm{p}<0.001)$. High proportions of patients had documentation of multidisciplinary team involvement at the time of transfer at baseline (mean $72.1 \%$ ). This increased to $99.3 \%$ in the follow up group $(p<0.001)$. Fewer patients had contact with a physiotherapist in the follow up group than at baseline (59.1\% $\vee 40.7 \%$, $\mathrm{p}=0.015)$, or with clinical nurse specialists (CNS) $(61.3 \% v$ $19.2 \%, \mathrm{p}<0.001)$. There were no differences in the proportions of young people seeing occupational therapists, psychologists, podiatrists, social workers, or dieticians. A few young people in both groups were also in contact with a variety of other health professionals including ophthalmologists, dentists/maxillofacial, dermatologists, orthopaedic surgeons, endocrinologists, gastroenterologists, renal physicians, and youth workers.

\section{The adult rheumatology interface}

With respect to the paediatric/adult care interface, similar proportions of young people were offered or actually made a preparatory visit to the adult clinics in each group $(21.4 \% \mathrm{~V}$ $34.2 \%, \mathrm{p}=0.06 ; 16.7 \% \vee 22.9 \%, \mathrm{p}=0.32$, respectively). There was improved documentation of whether an overlap visit to the paediatric clinic was made after the first adult clinic appointment $(72.2 \% \vee 88.2 \%, \mathrm{p}=0.004)$. The proportions of patients actually experiencing this was higher at follow up, but the difference was not significant $(26.4 \%$ v 39\%, $\mathrm{p}=0.076)$. More over 21 year olds were offered preparatory visits to adult clinics $(17.9 \% \vee 45.5 \%, \mathrm{p}=0.035)$, made these visits $(13.3 \% \vee 40 \%, \mathrm{p}=0.03)$, or had an overlap visit at the paediatric clinic $(23.1 \% \vee 57.1 \%, p=0.05)$ than the under 21s. Following transfer there was improved documentation as to whether there were any problems with respect to the transfer $(40.5 \% \vee 75.5 \%, \mathrm{p}=0.001)$ but no difference in the

Table 2 Comparison of the documentation of self advocacy development

\begin{tabular}{llll}
\hline & $\begin{array}{l}\text { Baseline, } \mathbf{n = 1 2 8} \\
\text { (\% documented) }\end{array}$ & $\begin{array}{l}\text { Follow up, } \mathbf{n = 9 3} \\
\text { (\% documented) }\end{array}$ & p Value \\
\hline $\begin{array}{l}\text { Age when independent visit concept } \\
\text { introduced }\end{array}$ & 14.1 & 49.5 & $<0.001$ \\
Age when independent visits began & 14.1 & 52.2 & $<0.001$ \\
Age when self medication discussed & 10.9 & 37.6 & $<0.001$ \\
Age when self medicating & 7.8 & 43 & $<0.001$ \\
Age when making own appointments & 11.7 & 16.9 & 0.29 \\
\hline
\end{tabular}




\begin{tabular}{|llll|}
\hline $\begin{array}{l}\text { Table } 3 \text { Comparison of self advocacy age related data: baseline } v \text { follow up (Mann- } \\
\text { Whitney U test) }\end{array}$ & $\begin{array}{l}\text { Baseline median years } \\
\text { (min, max) }\end{array}$ & $\begin{array}{l}\text { Follow up median years } \\
\text { (min, max) }\end{array}$ & p Value \\
\hline & $17(12,18.5)$ & $17(13,40)$ & 0.5 \\
\hline $\begin{array}{l}\text { Age at first discussion of transfer } \\
\text { Age at transfer to adult care }\end{array}$ & $18(12,49)$ & $18(15,40)$ & 0.26 \\
$\begin{array}{l}\text { Age when independent visit } \\
\text { concept introduced }\end{array}$ & $17(15,18)$ & $16(13,19)$ & 0.01 \\
$\begin{array}{l}\text { Age when independent visits } \\
\text { began }\end{array}$ & $16(15,19)$ & $17(12,20)$ & 0.98 \\
$\begin{array}{l}\text { Age when self medication } \\
\text { discussed }\end{array}$ & $14.5(12,19)$ & $15(14,18)$ & 0.3 \\
$\begin{array}{l}\text { Age when self medicating } \\
\text { Age when making own } \\
\text { appointments }\end{array}$ & $16.5(12,19)$ & $16(14,20)$ & 0.77 \\
\hline
\end{tabular}

proportions of young people experiencing problems (17.6\% $v$ $10.8 \%, \mathrm{p}=0.48$ ) or the proportion of cases where a letter was received from the adult rheumatologist (19.2\% $v 28.8 \%$, $\mathrm{p}=0.14$ )

\section{Transition issues and adolescent readiness}

There was significant improvement in the documentation of disease specific educational needs being addressed at follow up $(26.7 \% \quad v 87 \%$, respectively; $\mathrm{p}<0.001)$. There were improvements in the documentation of discussions regarding specific transitional issues for the follow up data (table 4) and significant improvements in the documentation of all aspects of adolescent readiness comparing baseline with follow up groups: decision making, communication skills, self care, independent visits, phoning with own queries (table 5).

There was increased documentation of preparation for joint injections without sedation in the follow up group $(5.4 \% \mathrm{v}$ $23.8 \%, p=0.008$ ) and fewer patients were having joint injections under general anaesthesia $(60 \% \vee 40 \%, \mathrm{p}=0.002)$ at follow up.

\section{Administrative issues}

More of the follow up group's medical notes contained a structured transition plan $(3.1 \% \vee 35.3 \%, \mathrm{p}<0.001)$ and more young people were provided with written information detailing the transition process $(1.3 \% \vee 21.3 \%, \mathrm{p}<0.001)$.
There was general improvement in documentation about whether summaries from all members of the MDT were sent to the adult clinic (table 6).

The actual proportions of patients having these summaries sent to the adult clinic significantly improved with respect to copies of discharge summaries, DEXA scans, Childhood Health Assessment Questionnaire (CHAQ) ${ }^{19}$ results, core outcome variables, ${ }^{20}$ and future management plans (table 3 ). Young people themselves were more likely to receive a copy clinic letter in the follow up group $(3.9 \% \vee 53.6 \%, \mathrm{p}<0.001)$ and to hold their own monitoring cards (17.9\% $v 32.3 \%$, $\mathrm{p}=0.04)$.

When the data were reanalysed excluding centre l, which was over-represented at follow up (42\% of case notes reviewed) (table 1), there was no change in the results except that a significant improvement in the age when self medication was discussed was now observed (excluding centre 1: age at baseline $=14.5$ (12 to 17) years; age at follow up $=14$ ( 14 to 20 ) years, $p=0.028$; compare table 3 ), although documentation of this information was incomplete from centre 1 (data available for eight of 39 at follow up; median age when self medication was discussed 17 years). There was also an improvement in the frequency of involvement of the consultant $(p=0.021)$, CNS $(p=0.001)$, and physiotherapist $(\mathrm{p}=0.002)$ in transition discussions. The male sex bias and the improvements in the documentation of provision of transition information leaflets, patient held

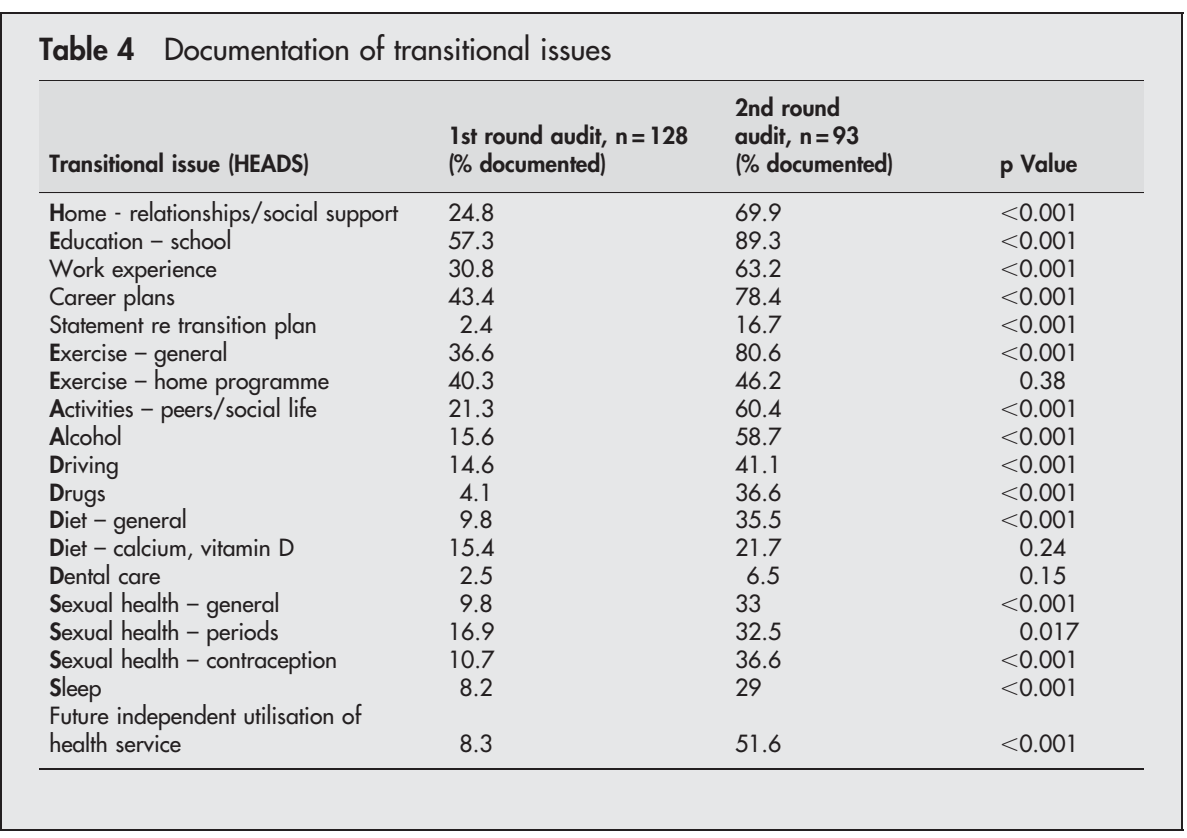


Table 5 Documentation of adolescent readiness

\begin{tabular}{lcll}
\hline Aspect of adolescent readiness & $\begin{array}{l}\text { Baseline, } \mathbf{n = 1 2 8} \\
\text { (\% documented) }\end{array}$ & $\begin{array}{l}\text { Follow up, } \mathbf{n = 9 3} \\
\text { (\% documented) }\end{array}$ & p Value \\
\hline Decision making & 7.9 & 63.6 & $<0.001$ \\
Communication skills & 10.4 & 75 & $<0.001$ \\
Self care & 12.8 & 80.7 & $<0.001$ \\
Independent visits & 13.5 & 66.3 & $<0.001$ \\
Phoning with own queries & 6.3 & 26.5 & $<0.001$ \\
\hline
\end{tabular}

monitoring cards, and offers of preparatory visits to the adult clinic were, however, lost.

When the follow up data were reanalysed comparing the results for those enrolled in the transitional care project, the populations were comparable in terms of sex, age at disease onset, co-morbidities, and disease subtypes. There was no significant difference in the actual ages of self advocacy development (as in table 2). Multidisciplinary involvement and the practice of sending copy letters to the young person were also better in the project patients $(72.2 \% \vee 46 \%$, $p=0.016$ ). Documentation of transitional care components, discussion of transitional issues, features of adolescent readiness, and parental needs were generally significantly better with a few interesting exceptions. No difference was observed between project participants and others in the following:

- transitional care components: preparatory visits to adult clinics, addressing disease specific educational needs;

- discussion of certain specific transitional issues as detailed in table 4: education - school, career plans, exercise (general/home), driving, diet, dental care, sleep;

- preparation for intra-articular injections done while awake;

- documentation of patients phoning with own queries;

- the majority of the paper based items transferred to the adult service (detailed in table 6) except for the medical summaries and core outcome variables.

\section{DISCUSSION}

The improved documentation of transitional issues in addition to some aspects of practice reported here highlights the immediate impact of research on clinical practice in terms of raising awareness beyond research participants in addition to the challenges of translating policy into practice. Process issues such as documentation are integral to transitional care, particularly in view of the multidimensional and

Table 6 Transfer process issues

\begin{tabular}{llll}
\hline Item sent to adult service & $\begin{array}{l}\text { Baseline } \\
\text { group (\%) }\end{array}$ & $\begin{array}{l}\text { Follow up } \\
\text { group (\%) }\end{array}$ & p Value \\
\hline Copy dinic letters & 50.8 & 59.3 & 0.21 \\
Copy discharge summaries & 1.8 & 20.3 & $<0.001$ \\
Medical summary & 77.1 & 77.9 & 0.708 \\
Plan for future management & 23 & 65.8 & $<0.001$ \\
Ophthalmology summary & 18.8 & 20.8 & 0.826 \\
Nursing summary & 8.5 & 8.4 & 0.984 \\
Physiotherapy summary & 13.2 & 17.8 & 0.46 \\
OT summary & 9.1 & 2.9 & 0.13 \\
DEXA scan results & 2.8 & 15.4 & 0.014 \\
CHAQ scores & 13.8 & 63.5 & $<0.001$ \\
Core outcome variables & 1.2 & 62.2 & $<0.001$ \\
Growth charts & 23.6 & 26.3 & 0.75 \\
\hline
\end{tabular}

CHAQ, Childhood Health Assessment Questionnaire; DEXA, dual energy $x$ ray absorptiometry; OT, occupational therapy. multidisciplinary nature of care provision, the latter requiring effective communication (including written) between professionals. Unfortunately the administrative workload of these process issues has currently not been adequately recognised to date. In view of the generic nature of the main findings reported here this study has potential wider relevance to all young people with chronic illnesses requiring transitional care.

\section{Timing}

Early introduction of the concept of transition is viewed as advantageous in preparing young people and their families for the move to adult care. ${ }^{21} 22$ Although this age criteria did improve at follow up, the median age was still 15.8 years, with no significant difference between the project participants and the rest. Preliminary results from the outcome data reveal significant benefits to starting transition at age 11 years, ${ }^{12}{ }^{13}$ earlier than that advocated by both the Royal College of Nursing (13 years ${ }^{8}$ and the American Academy of Pediatrics ("by age 14 years" ${ }^{\prime 6}$ )

There was a significant improvement at follow up in the time period between first discussion of transition and age at transfer of the patients studied (median gap $=0(0-4)$ years at baseline compared with $1(0-4)$ years at follow up, $\mathrm{p}<0.001$ ) which persisted even when the over 21 -year-olds were excluded. The timing of transfer from paediatric to adult services is influenced by many factors, chronological age being only one. Therefore it is generally agreed that, although is it useful to have a target age, flexibility regarding this is necessary ${ }^{9}$ and this should be applied to all stages of the transitional process.

\section{Self advocacy skills}

There was little change in the documented clinical practice of self advocacy skills training after the introduction of the transition project, or in the proportions of parents being seen alone, although there were improvements in the documentation. The project participants included in this audit, however, were primarily the 17 year old "control group", in that they were receiving transitional care relatively late in adolescence, the project being primarily aimed at early adolescence. The age when independent visits began was actually slightly older at follow up, though not significantly so, and relatively old when compared to the age proposed by the young people themselves ( $13-16$ years $)^{23}$ and by health care providers in other studies ( 12 years). ${ }^{24}$ Giving adolescents the option of being seen by professionals without their parents was one of six items identified in a Delphi study of users and providers as constituting best practice and being highly feasible. ${ }^{16}$ In a retrospective study of young adults with congenital heart disease, clinic visits without parents or siblings were associated with successful transfer. ${ }^{25}$ Promoting this can pose difficulties for health care professionals because of concern about negative responses or attitudes of parents and young people. However, when surveyed, professionals, patients and parents all agree that the option of being seen by professionals alone is an important aspect of transition but 
they have been shown to prioritise it differently. ${ }^{216}{ }^{24}$ Young people also need assurances of confidentiality if seeing health workers alone. This has been shown to increase the willingness to disclose sensitive information and to seek future care. ${ }^{26-28}$ Such assurance is important for young people with chronic disease as they may not be aware of this change as they grow up, ${ }^{13}$ having always been used to parents or carers being involved in the consultation.

\section{Multidisciplinary team involvement}

Multidisciplinary involvement was prevalent in the baseline and follow up groups, physiotherapist and occupational therapists being most commonly involved, with the exception of nurse specialists at baseline. However, nurse specialist involvement fell sharply in the follow up group. This could be explained by, first, other allied health professionals or medical staff, or both, undertaking primary roles in transition, including the impact of the local programme coordinator (LPC) role in the project ${ }^{10}{ }^{11}$; second, local resources, as exemplified by the improved results following the exclusion of centre 1, where there was no nurse specialist available in the adolescent clinic at the time of the study; and third, the bias of only medical notes being audited. This finding is, however, of interest as the coordinating role has primarily been identified as nursing in policies to date ${ }^{89}$ and supports the generic nature of this role, which can be undertaken by other allied health professionals. ${ }^{2}$

\section{The adult rheumatology interface}

Contact between paediatric and adult providers remained relatively low after the introduction of the transition project, as illustrated by the proportions of patients having overlap visits and the correspondence received from the adult providers. In view of this, the proportions of young people reported to have experienced problems after transfer may be artificially low as problems simply did not get communicated back to the paediatric teams. The increased frequency of preparatory visits to the adult service observed in the over-21year-olds raises interesting questions: does their maturity or experience allow them to communicate this need, or do they or their paediatric team have more problems letting go? The latter has been reported in other studies of childhood onset disease $^{29}$ and has been highlighted as a potential barrier to transfer. $^{30}$

Although participation in the project improved the frequency of preparatory visits actually made, the administrative transfer process was not significantly influenced by the project except for an increase in medical summaries, a template for which had been part of the project resource pack. ${ }^{11}$ Finding an interested and capable adult service has been highlighted as a major difficulty for young people, their families, and the paediatric services. ${ }^{21}{ }^{31}$ Collaboration with adult services has been cited as critical for the success of a transition programme $e^{32}$ and an essential component of it. ${ }^{93}$ In a survey of transfer methods for diabetic services it was found that higher rates of clinic attendance two years posttransfer were seen where young people had the opportunity to meet the adult diabetes consultant before transfer. ${ }^{34}$ Young people themselves are keen advocates of this practice in several studies. ${ }^{35-37}$

\section{Administrative issues}

Copies of clinic letters were more commonly sent to young people in the follow up group and particularly those in the research project, which included a template for such letters in the project resource pack. As from April 2004 this has been a standard for adult services in the United Kingdom. ${ }^{38}$ The acceptability of such practices for young people has not, however, been wholly determined. ${ }^{39}$ Ali and Charlton reported $69 \%$ of a small cohort of children over 11 years read and valued such letters highly. ${ }^{39}$ Therefore it is likely to be helpful to introduce this practice to transitioning adolescents before transfer, giving them the opportunity to become familiar with the general style of such letters; it may also identify unmet disease education needs which can then be addressed before transfer. Patient-held transfer summaries are also advocated in the Children's NSF for young people with special health care needs. ${ }^{9}$ Although the latter were not specifically addressed in this study, copy letters would obviously contribute to such practice.

The amount of information available to the adult teams remained limited although did improve at follow up for some aspects (table 3). However, approximately one third to a quarter of adult rheumatologists were not receiving copy clinic letters, a medical summary, CHAQ scores, or core outcome variables sent. Furthermore there was no change in the limited numbers with AHP (allied health professionals) summaries sent, which could be viewed as particularly important for the multidisciplinary nature of rheumatology, and for the potential differences in AHP service provision in the adult sector compared with the paediatric sector. Young people attending their first few adult clinic appointments may be very aware of this, noticing that the new adult clinic notes are much thinner than the thicker volumes they were familiar with in the paediatric clinic. This has potential psychological implications for the young person, reducing confidence in the adult team and exacerbating shyness, as they feel that they and their past and present problems are not known or appreciated. This could lead to the view that continuing to attend appointments in the adult clinic is a waste of their time. The ability to transfer appropriate information at the right time to the right people requires adequate administrative back up and this needs to be taken into account when planning transitional services. ${ }^{9}$

\section{Process}

Transition plans were significantly more prevalent in the medical notes following the introduction of the transitional project. This was largely due to the participants in the project in which such plans were integral. The use of such plans has been acknowledged as important in a national survey of professionals ${ }^{15}$ and recommended in national guidelines for transitional services, ${ }^{6-9}$ yet reported to be similarly deficient in a recent Australian study. ${ }^{40}$ The recent publication of generic transition plan proforma by the Royal College of Nursing will hopefully further support this area of practice development in the UK. ${ }^{8}$

The documentation of discussions regarding transitional issues generally improved with three exceptions. Dental care was seldom addressed and this is supported by two studies that found very poor dental health ${ }^{41}$ and increased periodontal disease ${ }^{42}$ in children and adolescents with JIA. Home exercise also remained poorly documented but perhaps this was included in the discussions around exercise in general, which did improve. The lack of both documentation and improvement in provision of dietary advice regarding calcium and vitamin $\mathrm{D}$ is concerning in view of the increasing awareness of osteoporosis risk in JIA ${ }^{43}$ and known prevalence of suboptimal intake in healthy adolescents ${ }^{44}$ although the precise role of supplementation in primary osteoporosis prevention in children remains unclear.

It is important that generic health issues are covered during transition, as they are often important concerns for adolescents with chronic illness. Adolescents with chronic illness are reported to have more age related health concerns than their healthy peers. ${ }^{45}$ These often have direct or indirect impact on the chronic disease-for example, alcohol consumption and sexual activity with respect to methotrexate 
Table 7 Priority areas in transitional care for further research and development

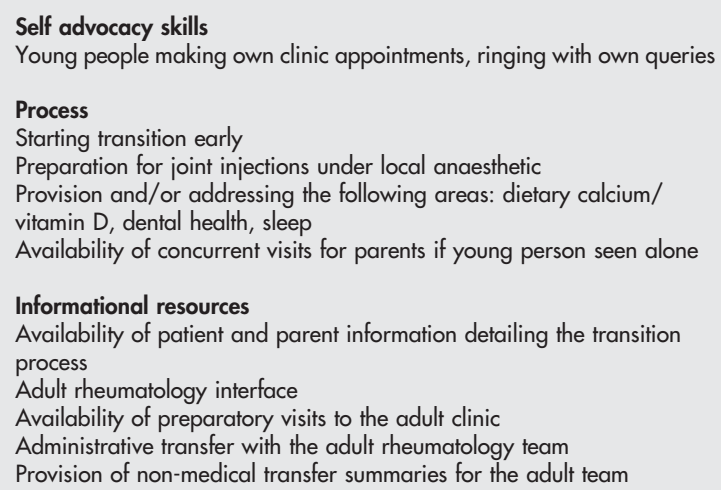

treatment. ${ }^{46}{ }^{47}$ Problems with conceiving and having miscarriages, menorrhagia, and pelvic inflammatory disease have been reported with increased frequency in young women with $\mathrm{JIA}^{48}$ Health professionals have reported difficulty addressing these issues, citing embarrassment, insufficient time, difficulty in finding the "right time", and insufficient training as the main barriers. ${ }^{46}$ The modified HEADS acronym is a useful aide memoire for this in clinical practice (see table 4 ).

In our comparison of consultation times within paediatric and adult rheumatology clinics, paediatric (including adolescent) consultations were on average twice as long as adult consultations. ${ }^{3}$ Timing of appointments and the availability of adequate staff, particularly if parents are going to be seen alone concurrently, need to be taken into consideration. The improvement of continuity of senior medical staff for consultations in the follow up group suggests that medical staff were indeed taking more of a lead in the transitional process and possibly freeing up specialist nurse time. Continuity of professionals has been highlighted as an important aspect of the transitional process for patients and their families. ${ }^{216}{ }^{49}$ However, this needs to be balanced with the preparation for the adult clinic, where often seeing the same doctor is not possible.

Differences in procedural pain management (for example, being unable to have joint injections with general anaesthesia) can be a major shock to young people with chronic illnesses moving on to adult clinics. This may influence their attendance at adult clinics and ultimately the potential for disease control. Preparation for this is required. The smaller proportion of young people having joint injections without a general anaesthetic in the follow up group indicates increased awareness of this difference between paediatric and adult practice. Apart from the age when the concept of an independent visit is introduced, there were no significant changes in the other age related transition process issues.

\section{Limitations of the study}

One of the main limitations of this study is that the lack of, or indeed the presence of, documentation does not necessarily reflect actual clinical practice. However, documentation of relevant information is important in view of the multidimensional and multidisciplinary nature of transitional care and therefore an audit of this aspect alone is of value. Another explanation of the discrepancies between documentation and change in practice reported here is the challenge of translating policy into practice. The reasons for this are likely to be multiple, including lack of training in this area for health professionals, inadequate numbers of health professional staff, and lack of administrative support..$^{15-17}$ However, increased awareness-as exemplified by improved documentation-is an important first step in this process and further research into the implementation of transitional care is ongoing. Table 7 details particular priority areas in which there was the least improvement at follow up and which need further investigation.

Another limitation of the study is that notes held by allied health professionals were not examined, only the medical notes. Once again, effective communication within the multidisciplinary team is vital in transitional care and may be enhanced in the future by increased use of individualised transition plans developed with the young person and available to all team members. ${ }^{8} 1115$

\section{Conclusion}

Before the transitional care project, the documentation of the transitional process in paediatric rheumatology medical notes in participating centres was limited. The improvement in this documentation suggests an increased awareness of transitional issues and needs of young people with chronic arthritis beyond those who were actually recruited into the project. The transitional care project had some impact in improving practice but this study suggests that the well defined principles underpinning transition ${ }^{4-9}{ }^{33}$ are yet to be fully translated into systematic approaches (including administrative infrastructure) that support transition to adult health care. Data analysis relating to the outcomes of the transitional care programme in terms of quality of life, satisfaction, and knowledge is ongoing. ${ }^{10} 1213$

\section{ACKNOWLEDGEMENTS}

This work was funded by a Special Purpose Grant (SO635) from the Arthritis Research Campaign (www.arc.org.uk) and undertaken on behalf of the British Paediatric and Adolescent Rheumatology Society, Children's Chronic Arthritis Association (www.ccaa.org.uk), Lady Hoare Trust for Physically Disabled Children (www.ladyhoaretrust.org.uk), and Arthritis Care (www.arthritiscare.org.uk).

We extend our sincere thanks to the South West Rheumatology Training Programme for funding an adolescent rheumatology fellowship for LPR at The Diana, Princess of Wales Children's Hospital, Birmingham; and to Bev Thomas, the project secretary. Contributors to the study were: Eileen Baildam, Diane Coulson, Joyce Davidson, Sue Ferguson, Helen Foster, Mark Friswell, Paul Galea, Janet Gardner-Medwin, Janine Hackett, Ann Hall, Gill Jackson, Jane Kelly, Sue Kemp, Nicki Kennedy, Ruth McGowan, Steph Phillips, Clarissa Pilkington, Sue Wyatt, Helena Wythe.

\section{Authors' affiliations}

L P Robertson, Derriford Hospital, Plymouth, UK

J E McDonagh, T R Southwood, K L Shaw, Institute of Child Health, University of Birmingham, Birmingham, UK

\section{REFERENCES}

1 Garwick AW, Kohrman C, Wolman C, Blum RW. Families' recommendations for improving services with chronic conditions. Arch Pediatr Adolesc Med 1998; 152:440-8.

2 Shaw KL, Southwood TR, McDonagh JE. User perspectives of transitional care for adolescents with juvenile idiopathic arthritis. Rheumatology 2004;43:770-8.

3 Robertson LP, Hickling P, Davis PJC, Bailey K, Ryder CAJ, McDonagh JE. Comparison of paediatric and adult rheumatology clinics. The doctor perspective [abstract]. Rheumatology 2003;42:97A.

4 Rosen DS. Transition from pediatric to adult-orientated health care for the adolescent with chronic illness or disability. Adolesc Med 1994;5:241-8.

5 Blum RW, Garell D, Hodgman CH, Jorissen TW, Okinow NA, Orr DP, et al. Transition from child-centred to adult health-care systems for adolescents with chronic conditions. A position paper of the Society for Adolescent Medicine. $J$ Adolesc Health 1993;14:570-6.

6 American Academy of Pediatrics, American Academy of Family Physicians, American College of Physicians-American Society of Internal Medicine. A consensus statement on health care transitions for young adults with special health care needs. Pediatrics 2002;110:1304-6.

7 Royal College of Paediatrics and Child Health. Bridging the gaps: health care for adolescents. June 2003, www.rcpch.ac.uk. 
8 Royal College of Nursing. Adolescent transition care: guidance for nursing staff, publication code 002313. London, RCN, 2004 (www.rcn.org.uk).

9 Department of Health. National service framework for children, young people and maternity services, September, 2004 (www.dh.gov.uk).

10 Shaw KL, Southwood TR, McDonagh JE, on behalf of the British Society of Paediatric and Adolescent Rheumatology. Growing up and moving on in rheumatology: a multicentre cohort of adolescents with juvenile idiopathic arthritis. Rheumatology 2005;44:806-12.

11 McDonagh JE, Southwood TR, Shaw KL. Growing up and moving on in rheumatology: development and preliminary evaluation of a transitional care programme for a multicentre cohort of adolescents with juvenile idiopathic arthritis. J Child Health Care, (in press).

12 Shaw KL, Southwood TR, McDonagh JE, on behalf of the British Society of Paediatric and Adolescent Rheumatology. Growing up and moving on in rheumatology: transitional care and quality of life in a multicentre cohort of adolescents with juvenile idiopathic arthritis (JIA). Rheumatology 2005;44(suppl 1):i92

13 McDonagh JE, Southwood TR, Shaw KL, on behalf of the British Society Paediatric and Adolescent Rheumatology. Growing up and moving on in rheumatology: disease knowledge in a multicentre cohort of adolescents with juvenile idiopathic arthritis (JIA). Arch Dis Child 2005;90(suppl II):A51.

14 McDonagh JE, Foster HE, Hall MA, Chamberlain MA. Audit of rheumatology services for adolescents and young adults in the UK. Rheumatology 2000;39:596-602

15 Shaw KL, Southwood TR, McDonagh JE. Developing a programme of transitional care for adolescents with juvenile idiopathic arthritis: results of a postal survey. Rheumatology 2004:43:211-19.

16 Shaw KL, Southwood TR, McDonagh JE. Transitional care for adolescents with juvenile idiopathic arthritis: a Delphi study. Rheumatology 2004;43:1000-6.

17 McDonagh JE, Southwood TR, Shaw KL, on behalf of the British Paediatric Rheumatology Group. Unmet educational needs of rheumatology health professionals in adolescent health and transitional care. Rheumatology 2004;43:737-43.

18 Robertson LP, Shaw KL, Southwood TR, McDonagh JE. An audit of patients with juvenile idiopathic arthritis recently transferred from paediatric to adult rheumatology clinics [abstract]. Rheumatology 2003:42:96A.

19 Nugent J, Ruperto N, Grainger J, Machado C, Sawhney S, Baildam E, et al The British version of the Childhood Health Assessment Questionnaire (CHAQ) and the Child Health questionnaire (CHQ). Clin Exp Rheum 2001;19(suppl 23): S163-7.

20 Giannini EH, Ruperto N, Ravelli A, Lovell DJ, Felson DT, Martini A. Preliminary definition of improvement in juvenile arthritis. Arthritis Rheum 1997;40:1202-9.

21 Reiss J, Gibson R. Health care transition: destinations unknown. Pediatrics 2002; 1 10:1307-14

22 Davies IH, Jenkins HR. Transition clinics for adolescents with chronic gastrointestinal disease in the UK and Ireland. J Pediatr Gastroenterol Nutr 2003;36:505-6.

23 Zack J, Jacobs CP, Keenan PM, Harney K, Woods ER, Colin AA, et al. Perspectives of patients with cystic fibrosis on preventive counselling and transition to adult care. Pediatr Pulmonol 2003;36:376-83.

24 Geenen SJ, Powers LE, Sells W. Understanding the role of health care providers during the transition of adolescents with disabilities and special health care needs. J Adolesc Health 2003;32:225-33.

25 Reid GJ, Irvine MJ, McCrindle BW, Sananes R, Ritvo PG, Sui SC, et al. Prevalence and correlates of successful transfer from pediatric to adult health care among a cohort of young adults with complex congenital heart defects. Pediatrics 2004;113:197-205.

26 Ford CA, Millstein SG, Halpern-Felsher BL, Irwin CE. Influences of physician confidentiality assurances on adolescents willingness to disclose information and seek future healthcare. A randomised controlled trial. JAMA 1997;278:1029-34.
27 Oppong-Odiseng AC, Heycock EG. Adolescent health services - through their eyes. Arch Dis Child 1997;77:115-19.

28 Thrall JS, McCloskey L, Ettner SL, Rothman E, Tighe JE, Emans SJ. Confidentiality and adolescents' use of providers for health information and pelvic examinations. Arch Pediatr Adolesc Med 2000;154:885-92.

29 Flume PA, Anderson DL, Hardy KK, Gray S. Transition programs in cystic fibrosis centers: perceptions of pediatric and adult program directors. Pediatr Pulmonol 2001;31:443-50.

30 Fox A. Physicians as barriers to successful transitional care. Int J Adolesc Health 2002; 14:3-7.

31 Scal P. Transition for youth with chronic conditions: primary care physicians' approaches. Pediatrics 2002;110:1315-21.

32 Kelly AM, Kratz B, Bielski, Rinehart PM. Implementing transitions for youth with complex chronic conditions using the medical home model. Pediatrics 2002; 1 10:1322-27.

33 Viner RM. Transition from paediatric to adult care. Bridging the gaps or passing the buck? Arch Dis Child 1999;81:271-5.

34 Kipps S, Bahu T, Ong K, Ackland FM, Brown RS, Foxt CT, et al. Current methods of transfer of young people with type 1 diabetes to adult services. Diabet Med 2002; 19:649-54.

35 Boyle MP, Farukhi Z, Nosky ML. Strategies for improving transition to adult cystic fibrosis care, based on patient and parent views. Pediatr Pulmonol 2001;32:428-36

36 Steinkamp G, Ullrich G, Muller C, Fabel H, von der Hardt. Transition of adult patients with cystic fibrosis from paediatric to adult care - the patients' perspective before and after start-up of an adult clinic. Eur J Med Res $2001: 6: 85-92$

37 Abdale B, Kuhl K, Tullis DE. Evaluation of patient satisfaction with the transition from a pediatric hospital to an adult centre [abstract]. Pediatr Pulmonol 1994; (suppl 10):NR403.

38 Department of Health. The NHS Plan. London: Stationery Office, 2000, (copy letter directive)

39 Ali F, Charlton CPJ. Does copying letters to patients make for better education? [abstract] Arch Dis Child, 2004;89(suppl 1):A29.

40 Lam PY, Fitzgerald BB, Sawyer SM. Young adults in children's hospitals: why are they there? Med J Aust 2005;182:381-4

41 Welbury RR, Thomasen JM, Fitzgerald OM, Steen IN, Marshall NJ, Foster HE. Increased prevalence of dental caries and poor oral hygiene in juvenile idiopathic arthritis. Rheumatology 2003;42:1445-51.

42 Miranda LA, Fischer RG, Sztanjnbok FR, Figueredo CM, Gustafsson A Peridontal conditions in patients with juvenile idiopathic arthritis. J Clin Peridontal 2003:30:969-74.

43 French AR, Mason T, Nelson AM, Crowson CS, O'Fallon WM, Khosla S, et al. Osteopaenia in adults with a history of juvenile rheumatoid arthritis. A population based study. J Rheumatol 2002;29:1065-70.

44 Gregory J, Lowe S, Bates CJ, et al. National Diet and Nutrition survey: young people aged 4 to 18 years, vol 1. London: HMSO, 2000.

45 Carroll G, Massarelli E, Opzoomer A, Pekeles G, Pedneault M, Frappier JY, et al. Adolescents with chronic disease: are they receiving comprehensive health care? J Adolesc Health Care 1983;17:32-6.

46 Britto MT, Rosenthal SL, Taylor J, Passo MH. Improving rheumatologists' screening for alcohol use and sexual activity. Arch Pediatr Adolesc Med 2000; 154:478-83

47 Nash AA, Britto MT, Lovell DJ, Passo MH, Rosenthal SL. Substance use among adolescents with juvenile rheumatoid arthritis. Arthritis Care Res 1998;11:391-6.

48 Ostensen M, Almberg K, Koksvik HS. Sex, reproduction and gynecological disease in young adults with a history of juvenile chronic arthritis. J Rheumatol 2000;27:1783-7

49 Beresford BA, Sloper P. Chronically ill adolescents' experiences of communicating with doctors: a qualitative study. J Adolesc Health 2003;33:172-9. 